\title{
Acoustic Detection of Faults and Degradation in a High-Bypass Turbofan Engine During Vehicle Integrated Propulsion Research (VIPR) Phase III Testing
}

\section{Devin K. Boyle}

NASA Armstrong Flight Research Center 


\section{Outline}

- Background on VIPR research

- Introduction to VIPR acoustics research objectives

- Motivation

- Test setup

- Volcanic Ash Ingestion Test Results

- 14th Stage Bleed Valve Simulated Failure Results

- Station 2.5 Bleed Valve Simulated Failure Results

- Conclusion 


\section{VIPR Background}

- Vehicle Integrated Propulsion Research (VIPR) project concluded Phase III of ground-based engine testing in Summer 2015

- Modified pre-production F117-PW-100 engine (military variant of PW 2000 used on the Boeing 757 ) in the 40k-lb thrust class

- Engines are representative of typical high-bypass commercial turbofans

- VIPR offered a way to introduce damaging faults that would otherwise be prohibitive 


\section{VIPR Overview}

Vehicle Integrated Propulsion Research (VIPR) engine tests to support the research and development of Engine Health Management Technologies for Aviation Safety Engine testing is a necessary and challenging component of Aviation Safety technology development.

Partnerships make it possible.

\section{Test Objectives:}

Demonstrate capability of advanced health management technologies for detecting and diagnosing incipient engine faults before they become a safety impact and to minimize loss of capability Approach:

Perform engine ground tests using high-bypass transport engine

- Normal engine operations

- Seeded mechanical faults

- Seeded gas path faults

- Accelerated engine life degradation through volcanic ash ingestion testing

Partnerships:

- NASA

- US Air Force

- Federal Aviation Administration

- Pratt \& Whitney

- GE

- Rolls-Royce

- United States Geological Survey

- Boeing

- Makel Engineering

- Others in discussion
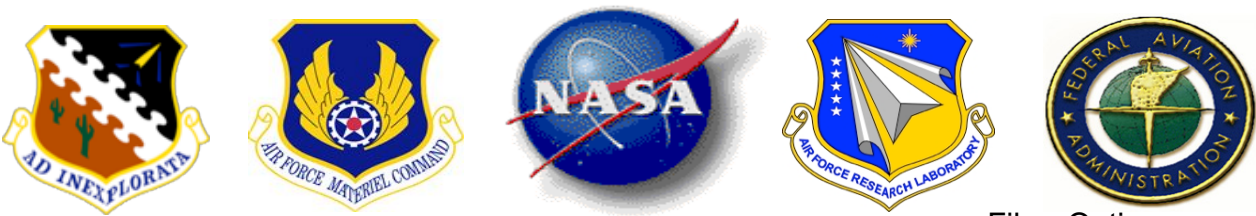

Fiber Optic Temperature

Dynamic Pressure Sensors

Sensors

SDA and High Freq Vibration Sensors

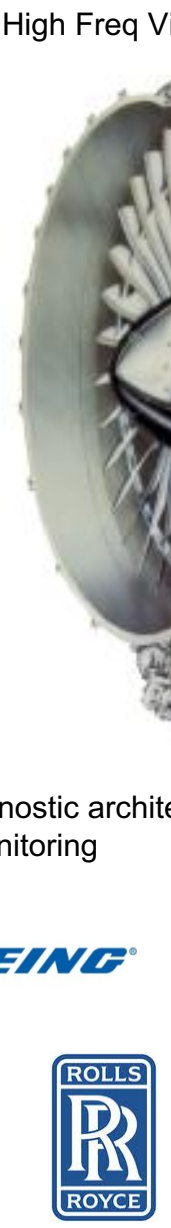

Model-based gas path diagnostic architecture Acoustic Engine Health Monitoring
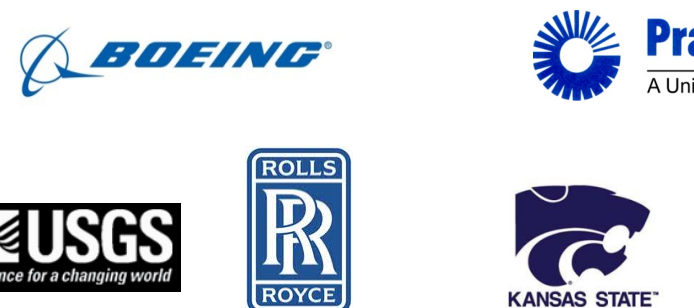

Microwave Tip Clearance Sensors

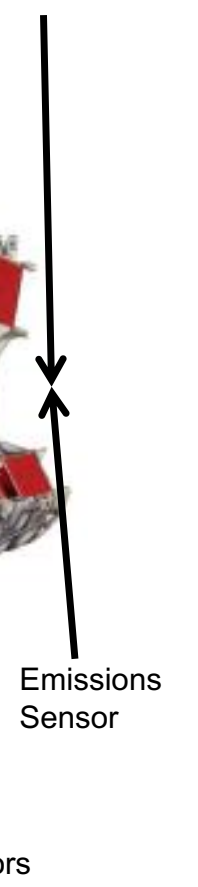

SDA and High Freq Vibration Sensors

Thin Film Sensors

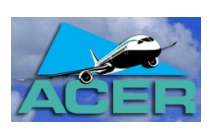

Annited Technologies Company

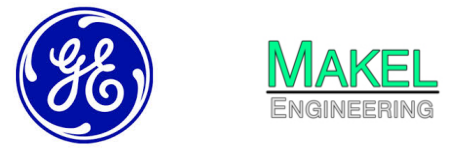




\section{VIPR III Overview}

\section{- VIPR III Test Objectives (Summer 2015)}

- Engine Health Management (NASA):

- Initial steps toward EHM sensor fusion with advanced sensors

- Demonstrate capability of advanced health management technologies for detecting and diagnosing incipient engine faults before they become a safety impact and to minimize loss of capability

- Volcanic Ash Ingestion Testing (AFRL and Partners)

- Run engine to end of life (negative EGT margin)

- Engine came out of overhaul with a fairly large positive margin

- Goal was to run engine through accelerated performance degradation with research instrumentation collecting data throughout

- To improve understanding of the effect on the engine of several hours of exposure to low to moderate concentrations of volcanic ash

- Determine how well engine degradation from volcanic ash is detected with an expanded engine health management system

- Pratt \& Whitney Testing

- Bleed Air Environment Testing (Boeing and Partners) 


\section{VIPR Acoustics Research}

- Goal: Characterize the engine core, fan, and exhaust acoustics under nominal and offnominal/seeded fault conditions

- Faults introduced during VIPR III included the simulated failures of the engine station 2.5 and $14^{\text {th }}$ stage bleed valves to their failsafe positions as well as the accelerated performance degradation of the engine due to volcanic ash ingestion 


\section{Motivation}

- The use of acoustics, if proven successful in detecting and potentially identifying faults, can progress toward condition-based maintenance

-Ultimate goal is detection and eventual identification of common faults

- External acoustic measurements of engines is a simple and non-intrusive inspection process

- Additionally, microphones may characterize the progression of engine operational degradation

- System doesn't have to survive the harsh environment of an engine installation in its current form 


\section{Test Setup}

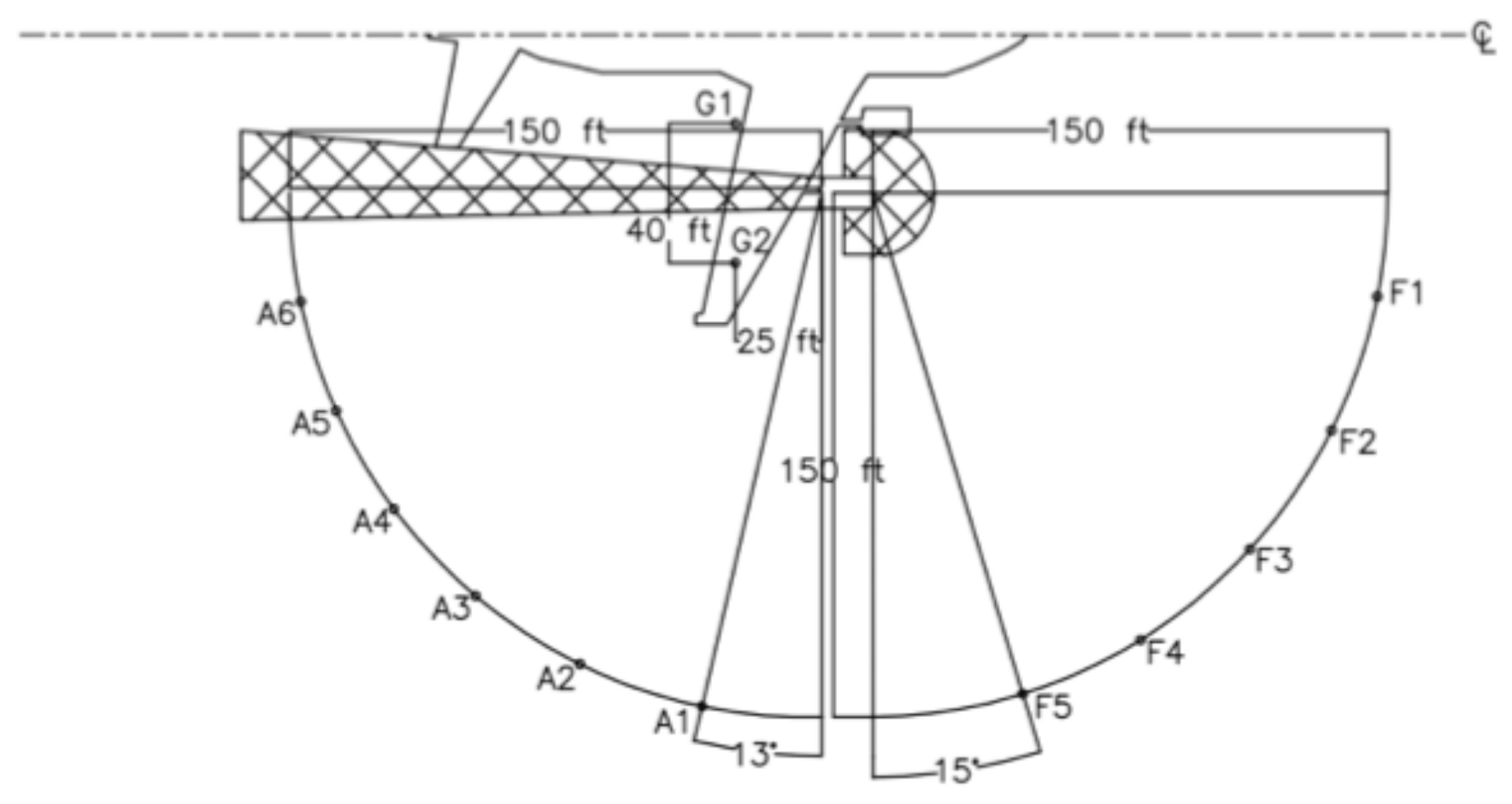

- $11 \times 1 / 2 "$ microphones in far-field radial array relative to inlet and core exhaust planes

- $2 \times 1 / 4 "$ microphones in near-field of exhaust plane

- All mics mounted inverted one microphone diameter above steel plate 


\section{Test Setup (Continued)}

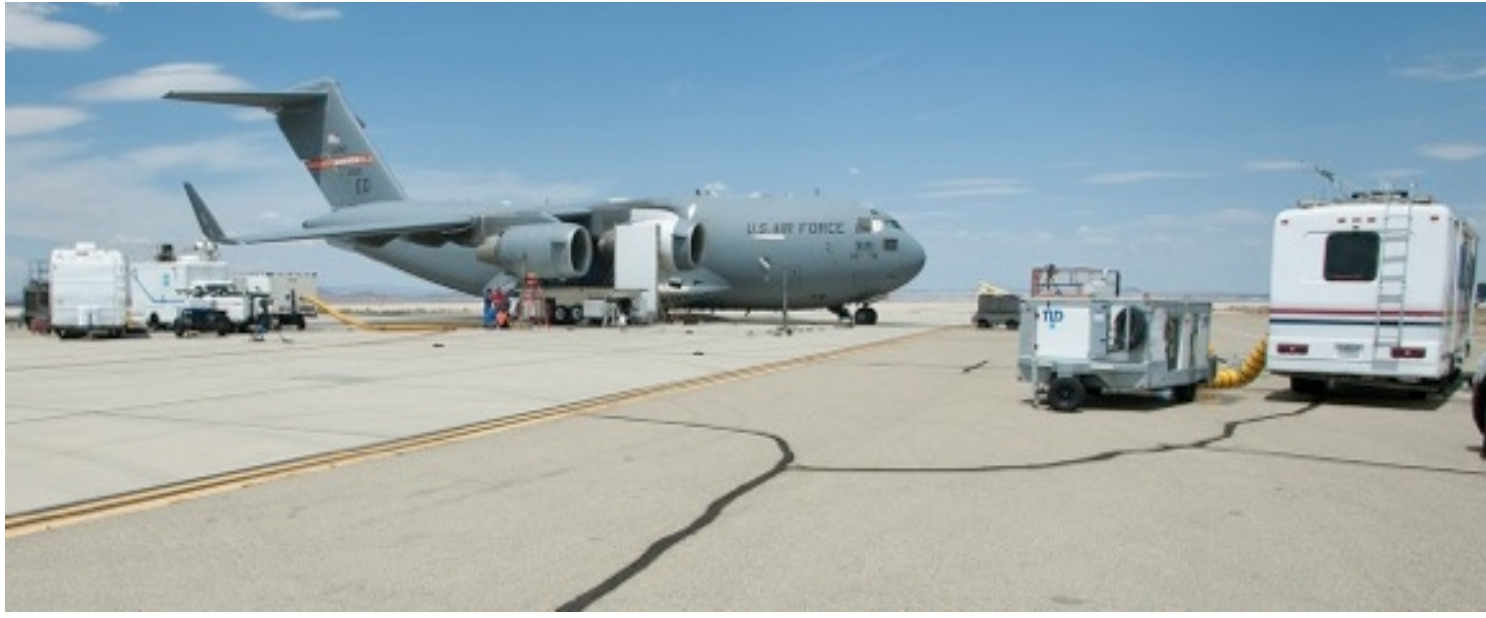

NASA Photograph ED15-0188-165

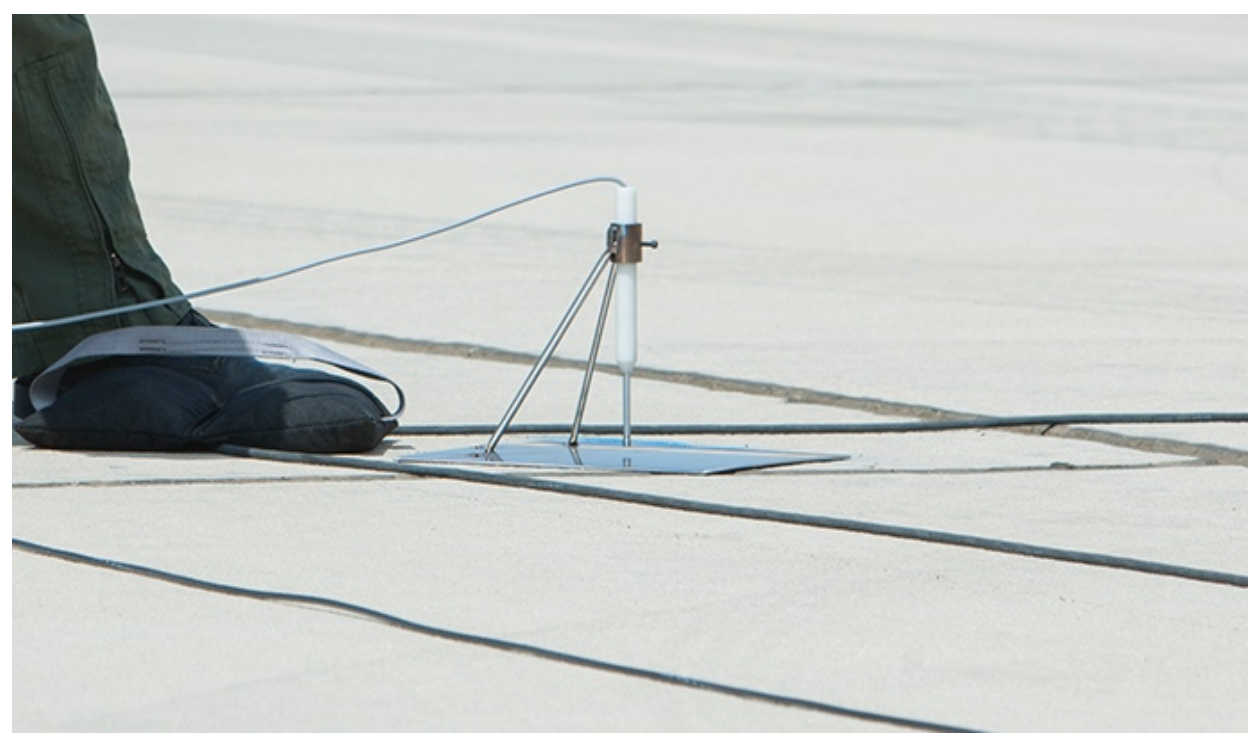

NASA Photograph ED15-0188-284

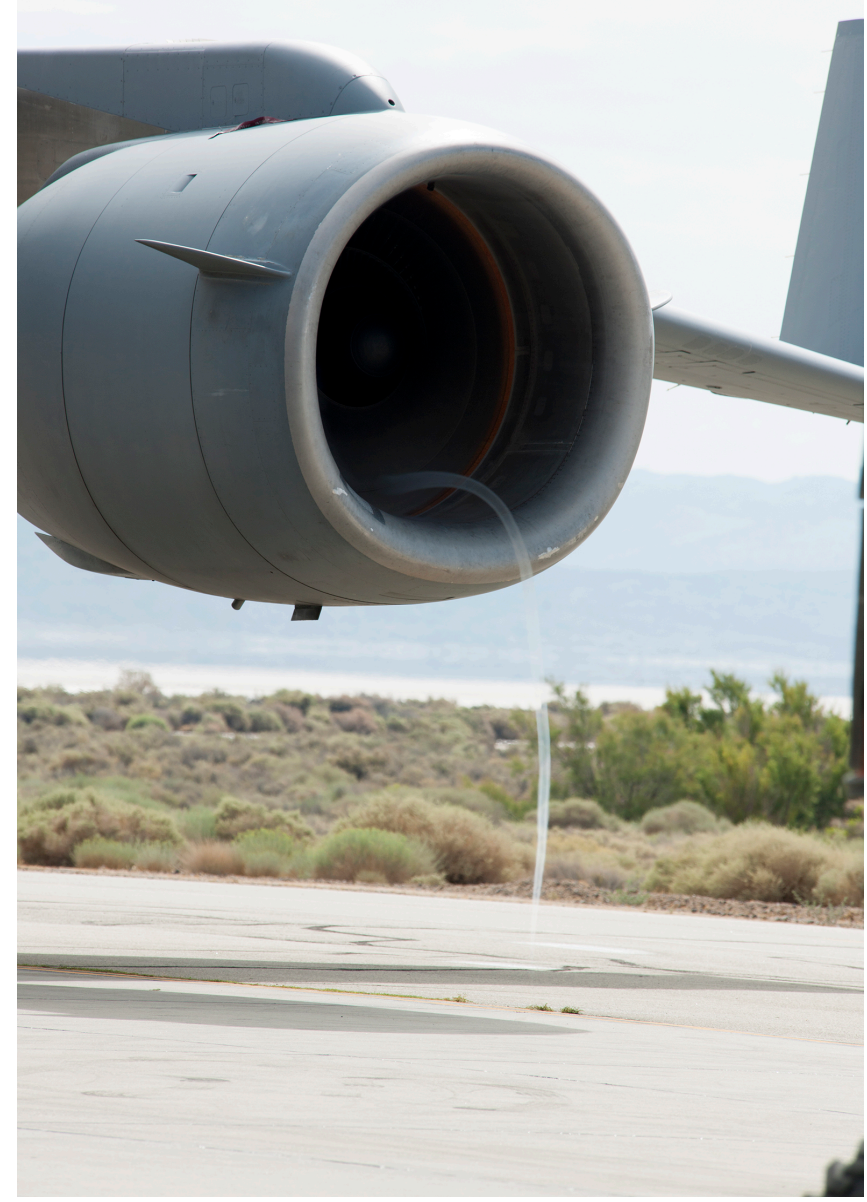

NASA Photograph ED15-0188-1005 


\section{Volcanic Ash Ingestion Testing Context}

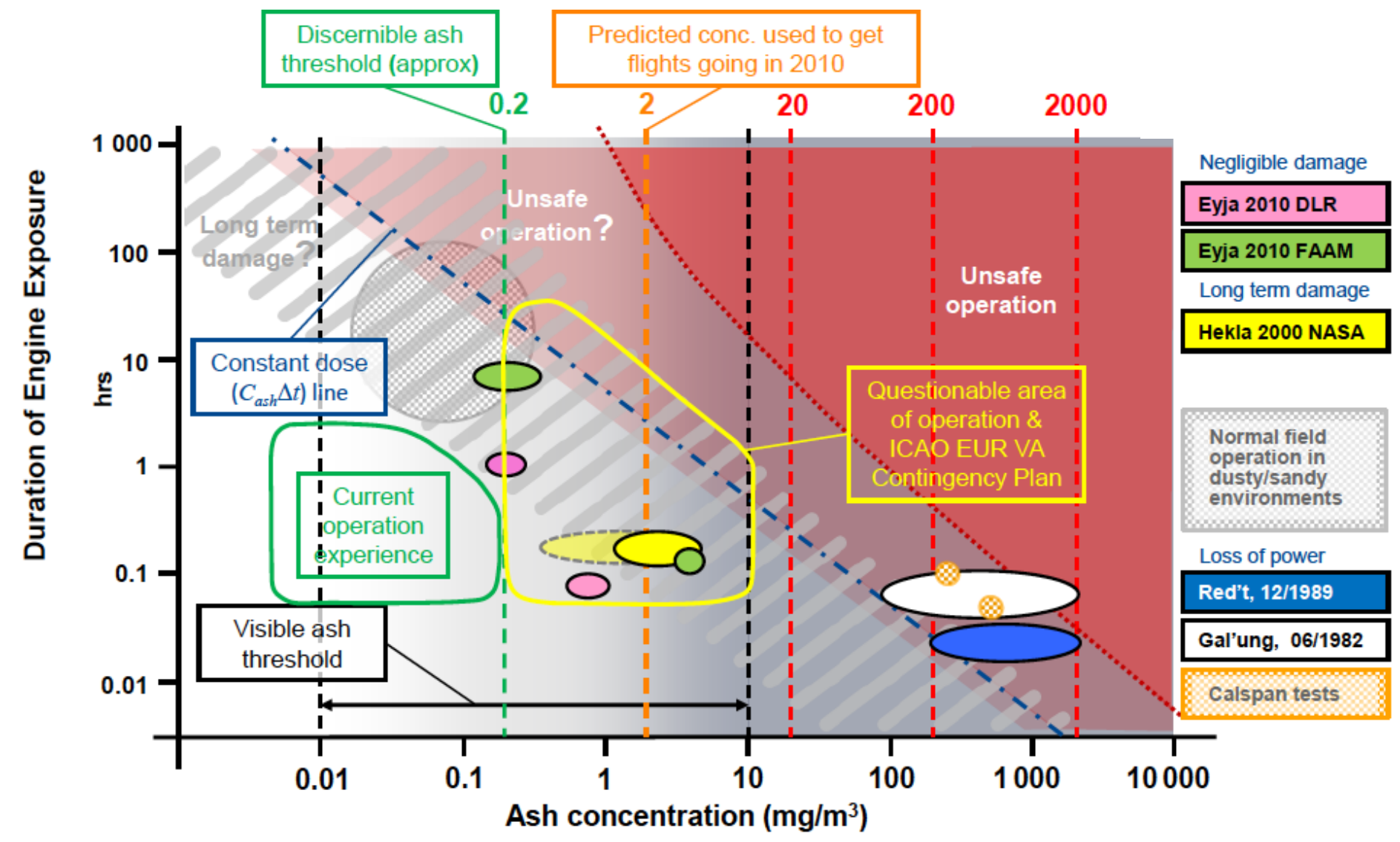

- Duration of Exposure v. Ash Concentration (DEvAC Chart), used with permission (C) 2015 Rolls Royce PLC 


\section{Volcanic Ash Ingestion Testing}

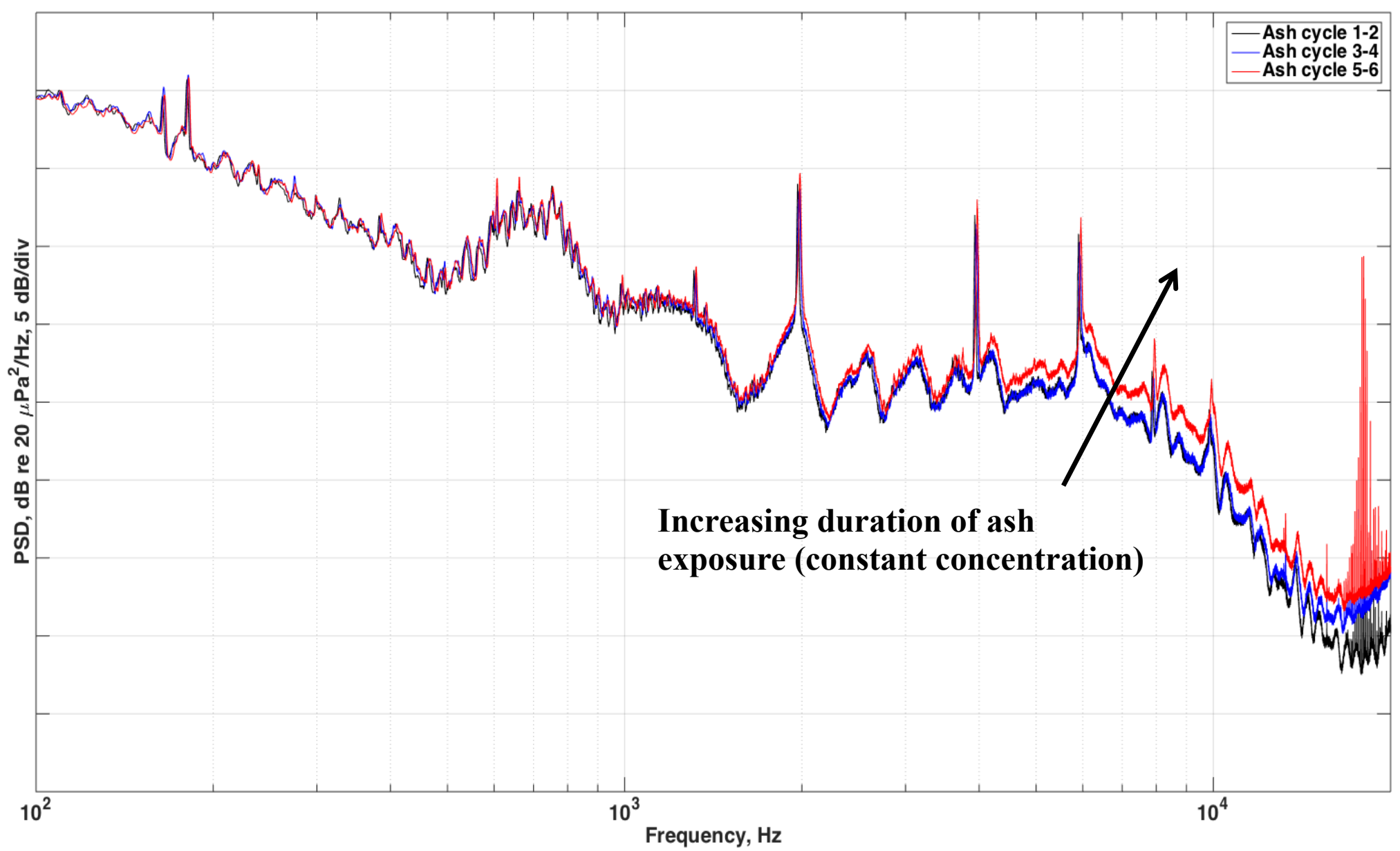

- Aft microphone A5 PSD for multiple cycles of volcanic ash ingestion at $10 \mathrm{mg} / \mathrm{m}^{3}$ (Day 1 of higher-concentration) 


\section{Volcanic Ash Ingestion Testing}

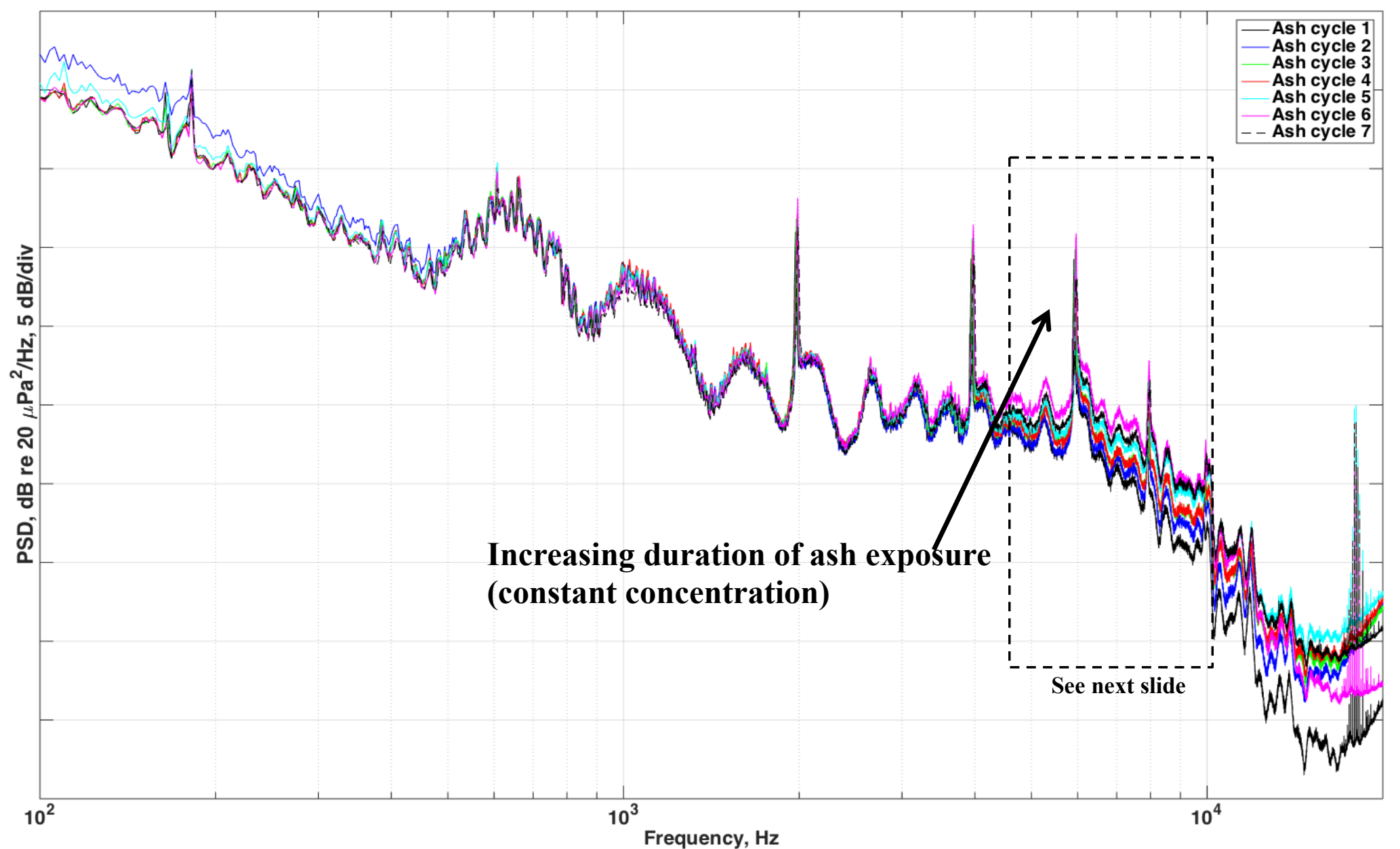

- Aft microphone A5 PSD for multiple cycles of volcanic ash ingestion at $10 \mathrm{mg} / \mathrm{m}^{3}$ (Day 2 of higher-concentration) 


\section{Volcanic Ash Ingestion Testing}

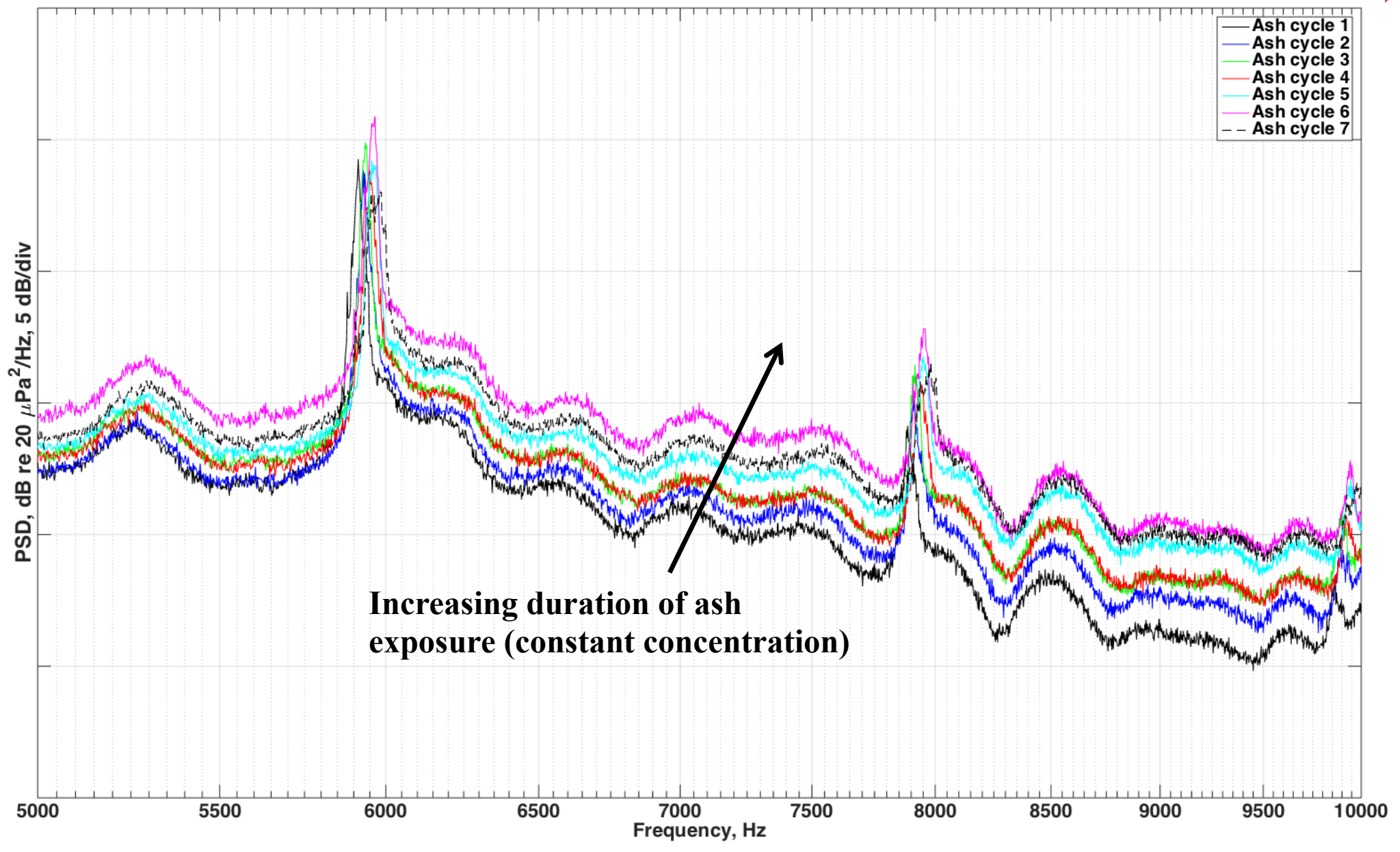

- Aft microphone A5 PSD for multiple cycles of volcanic ash ingestion at $10 \mathrm{mg} / \mathrm{m}^{3}$ (Day 2 of higher-concentration) 


\section{Research Engine (F117-PW-100)}

$14^{\text {th }}$ Stage (HPC)

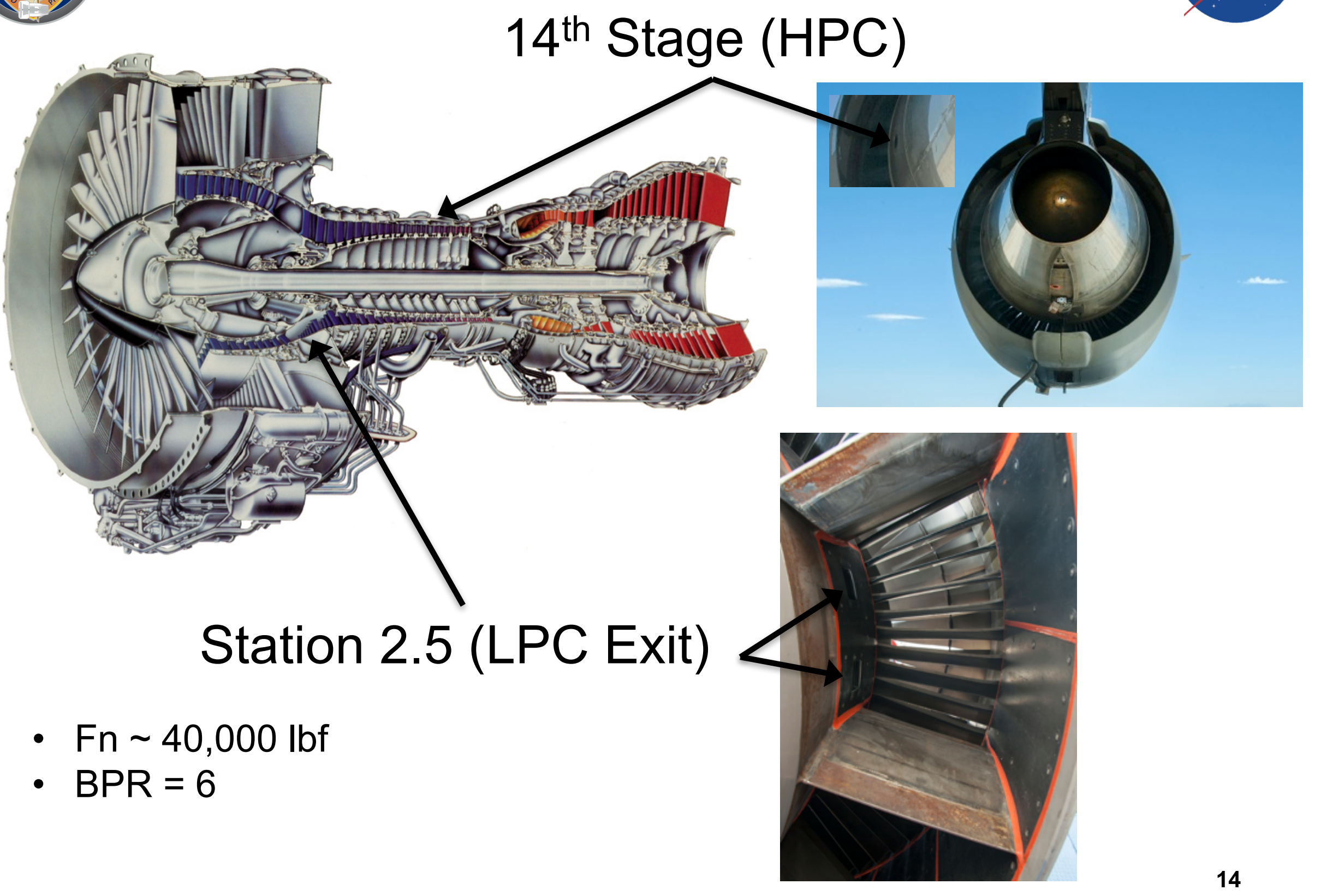




\section{Simulated Failure of $14^{\text {th }}$ Stage Bleed Valve}

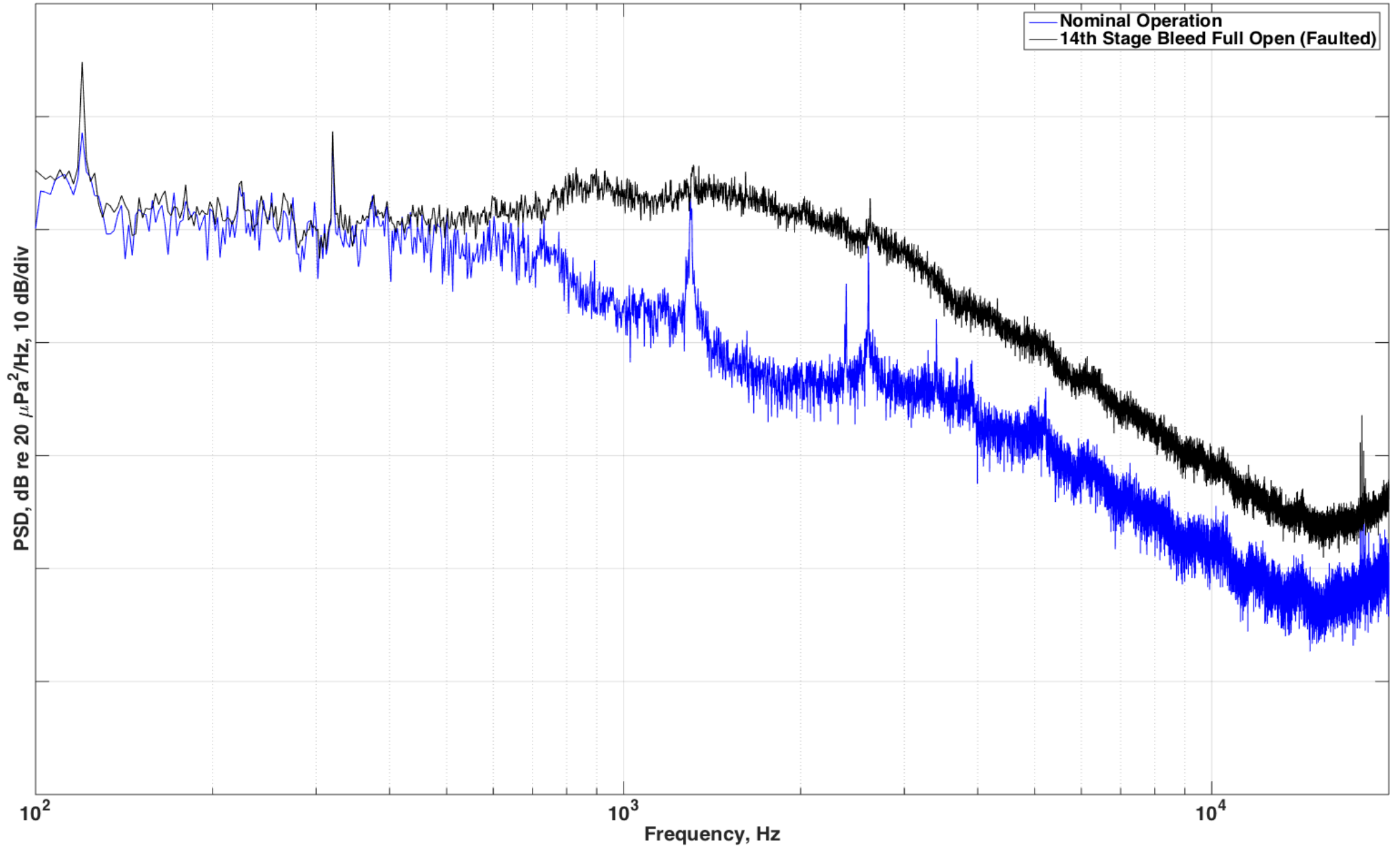

- Microphone A4 simulated failure of $14^{\text {th }}$ stage bleed valve to full-open failsafe position during steady state operation of engine 


\section{Simulated Failure of $14^{\text {th }}$ Stage Bleed Valve}

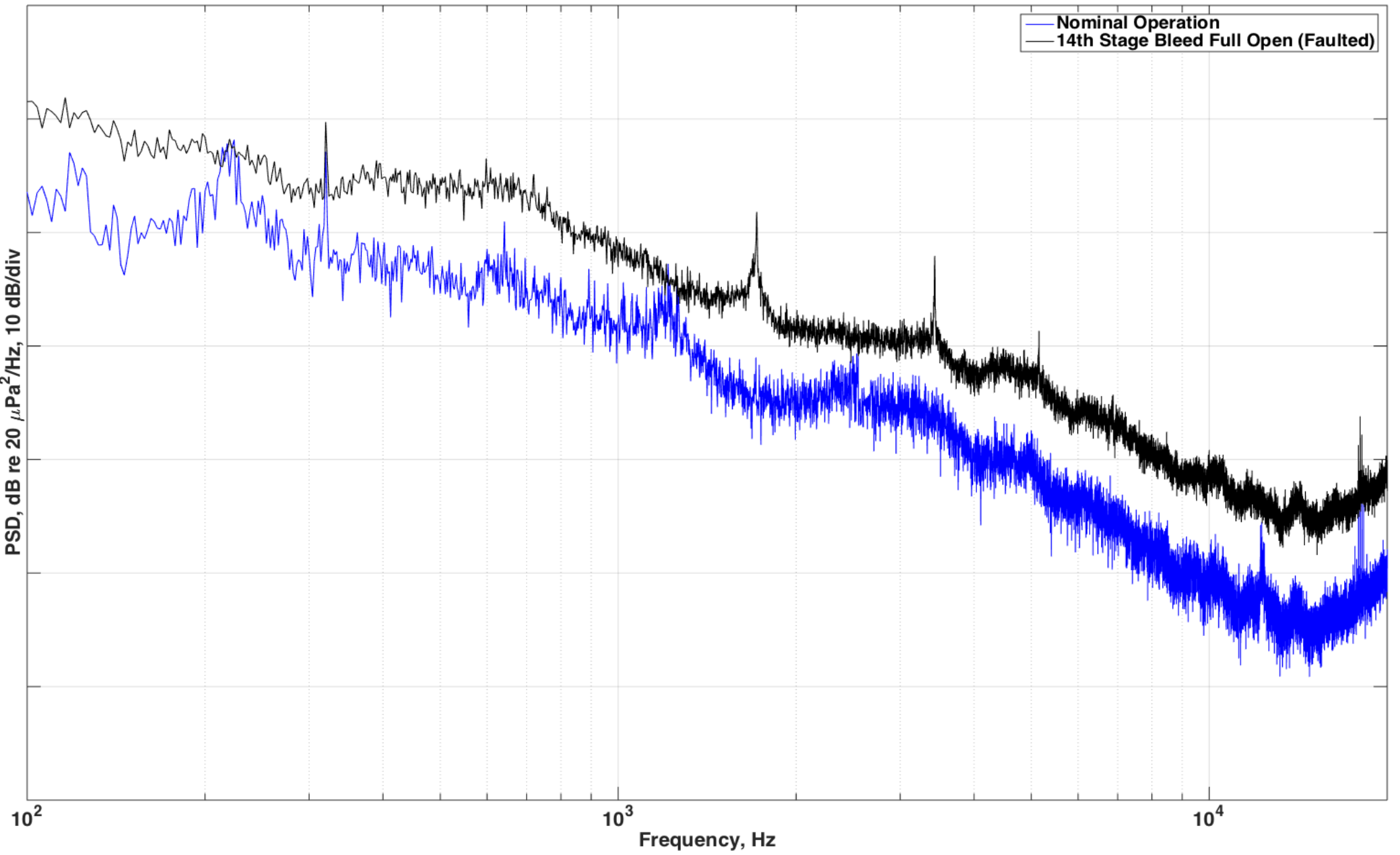

- Microphone A4 simulated failure of $14^{\text {th }}$ stage bleed valve to full-open failsafe position during ramp acceleration of engine 


\section{Simulated Failure of $14^{\text {th }}$ Stage Bleed Valve}

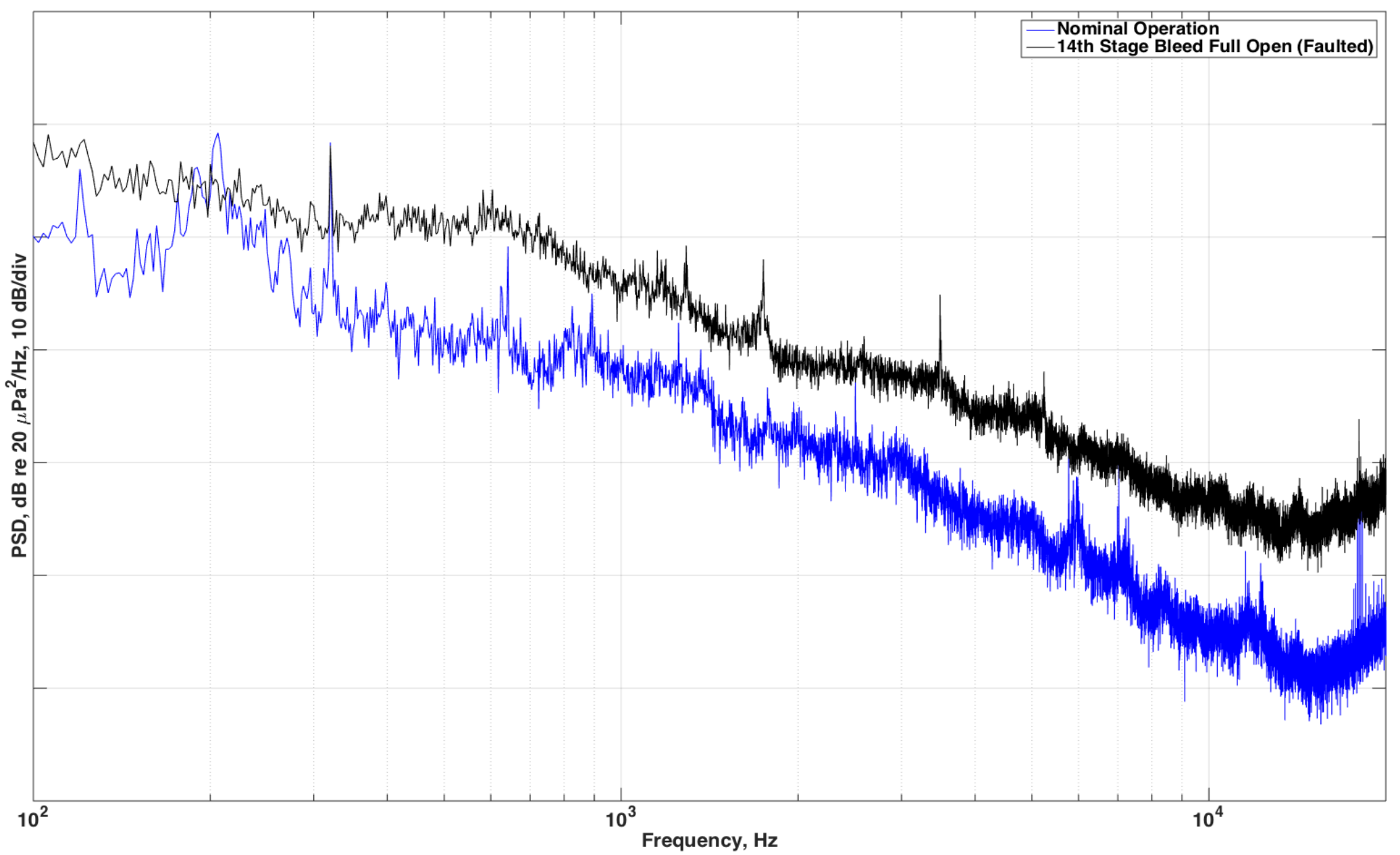

- Microphone A4 simulated failure of $14^{\text {th }}$ stage bleed valve to full-open failsafe position during snap acceleration of engine 


\section{Station 2.5}

- Acoustic changes due to simulated faulting of the station 2.5 bleed valve were more subtle

- Several factors contributed to this:

-Pressure at the $14^{\text {th }}$ stage bleed valve is an order of magnitude greater than at station 2.5

-Station 2.5 modulates as the engine transitions between idle and max power, whereas $14^{\text {th }}$ stage valve is discrete (fully closed to "failed" fully open)

-Station 2.5 exhausts bleed air through distributed manifold rather than single location 


\section{Simulated Failure of Station 2.5 Bleed Valve}

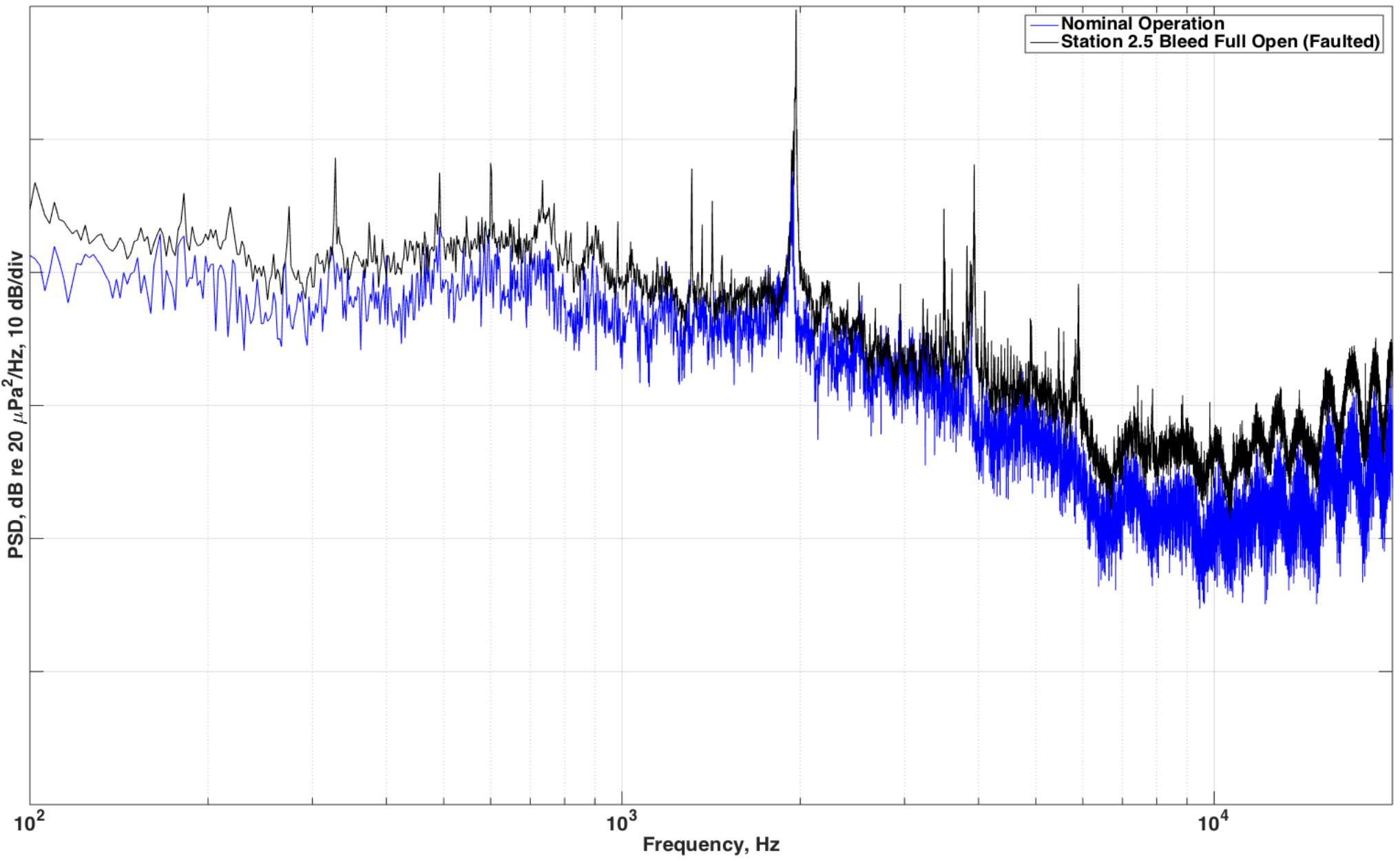

- Microphone F1 simulated failure of station 2.5 bleed valve to full-open failsafe position during snap acceleration of engine 


\section{Conclusion}

- Correlation between changes to engine's acoustic power spectral density and cumulative ingestion of volcanic ash suggests causation from mechanisms in engine core

- Simulated failure of $14^{\text {th }}$ stage bleed valve to its failsafe position detected by far-field acoustic microphone array

- Fault of station 2.5 bleed valve proved more difficult to detect

- The results offer justification for continuation of work in this area

- Next steps could include characterization of the acoustic changes for diagnostic applications 


\section{Acknowledgements}

- NASA Armstrong Flight Research Center Center Innovation Fund provided funding for procurement and labor

- Several employees helped in the somewhat arduous daily task of setup and teardown during testing

- Input from GRC acoustics researchers on improving mounting methods and tips on postprocessing data 


\section{Questions?}

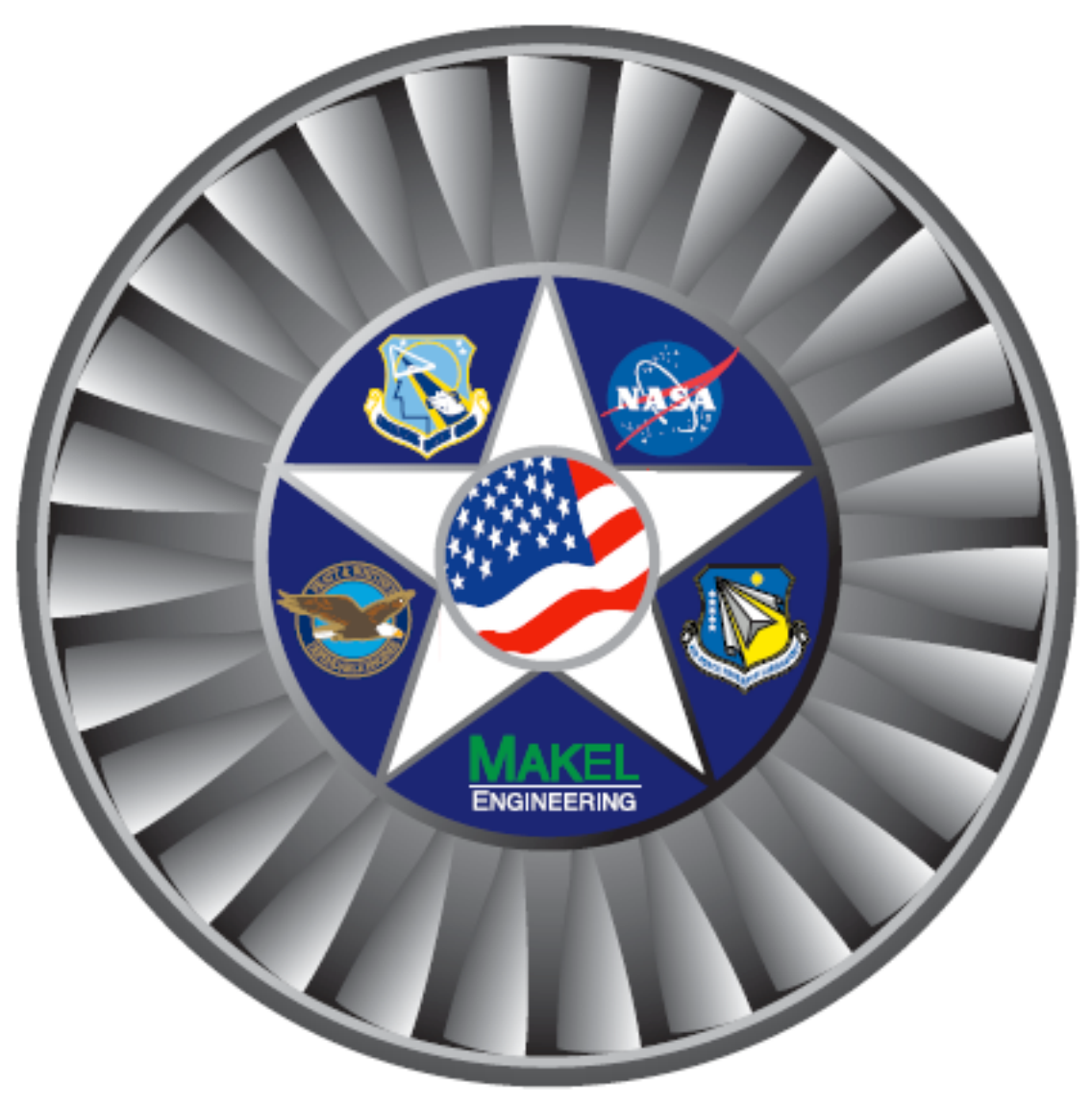

